\title{
L'escape room com a eina educativa per treballar la literatura a secundària: una proposta pràctica de Romeu i Julieta
}

\author{
Esther Martínez-Borobio ${ }^{1}$ (D), Eleonora Nakova-Katileva ${ }^{2}$ (D) \\ Article d'innovació. Rebut: 15/07/2019. Acceptat: 29/11/2019. Publicat a l'avançada: 24/01/2020. Publicat: 01/07/2020
}

Resum

INTRODUCCIÓ. En els darrers anys, la tendència educativa de ludificar les classes ha esdevingut un canvi important en l'ensenyament. Aquest article tracta sobre l'ús de l'escape room com a eina educativa per introduir la literatura en Ilengua anglesa a secundària. En concret, s'hi descriu una proposta per a 4 t de l'ESO on es treballa l'obra Romeu i Julieta de William Shakespeare, amb l'objectiu principal d'endinsar l'alumnat en l'estudi literari.

MÈTODE. El punt de partida d'aquesta proposta va ser la visualització de la pel·lícula Shakespeare in Love de John Madden, llargmetratge que il-lustra la vida de l'autor i que descriu el procés de creació de Romeu i Julieta, així com l'estudi sobre els aspectes principals de l'època i del gènere dramàtic. Un cop assolits aquests coneixements, l'alumnat havia d'aplicar allò après i treballar cooperativament per resoldre una sèrie d'enigmes relacionats amb l'obra de Romeu i Julieta.

RESULTATS. L'alumnat va adquirir nous coneixements sobre l'autor i l'obra d'una forma lúdica i va valorar la proposta de tipus escape room molt positivament.

DISCUSSIÓ. Considerant que actualment l'alumnat a qui s'adreça desconeix molts aspectes de la vida i obra de Shakespeare, aquesta unitat ens permet desenvolupar les competències de la dimensió literària d'una manera activa i motivadora.

\section{Paraules clau}

Innovació pedagògica; Ensenyament secundari; Breakout edu; Escape room; Llengua anglesa; Literatura; Competències.

Dades de les autores

${ }^{1}$ Institut Jaume Balmes, Espanya. Doctora en Filologia Hispànica per la Universitat de Barcelona, treballa com a professora d’Anglès i de Llengua Castellana i Literatura a l'ensenyament secundari. Correu per a la correspondència: emart365@xtec.cat

2 Institut Jaume Balmes, Espanya. Graduada en Estudis Anglesos per la Universitat de València. Màster en Educació i TIC per la Universitat Oberta de Catalunya. Treballa com a professora d'Anglès a l'ensenyament secundari.

\section{Referència recomanada}

Martínez-Borobio, E., i Nakova-Katileva, E. (2020). L'escape room com a eina educativa per treballar la literatura a secundària: una proposta pràctica de Romeu i Julieta. REIRE Revista d'Innovació i Recerca en Educació, 13(2), 1-18. https://doi.org/10.1344/reire2020.13.228965

(c) 2020 Esther Martínez-Borobio i Eleonora Nakova-Katileva. Aquest article és d'accés obert subjecte a la llicència de Reconeixement 4.0 Internacional Creative Commons, la qual permet utilitzar, distribuir i reproduir per qualsevol mitjà sense restriccions sempre i quan se citi adequadament l'obra original. Per veure una còpia de la llicència, visiteu http://creativecommons.org/licenses/by/4.0/ 
E. Martínez-Borobio i E. Nakova-Katileva. L'escape room com a eina educativa per treballar la literatura a secundària: una proposta pràctica de Julieta Título

El escape room como herramienta educativa para trabajar la literatura en secundaria: una propuesta práctica de Romeo y Julieta

Resumen

INTRODUCCIÓN. En los últimos años, la tendencia educativa de gamificar las clases se ha convertido en un cambio importante en la enseñanza. El presente artículo trata sobre el uso del escape room como herramienta educativa para introducir la literatura en lengua inglesa en secundaria. En concreto, se describe una propuesta para 4ㅇ de la ESO, en la que se trabaja la obra Romeo y Julieta de William Shakespeare, el objetivo principal de la cual es que el alumnado se adentre en el estudio literario.

MÉTODO. Esta propuesta parte de la visualización de la película Shakespeare in Love de John Madden, largometraje que ilustra la vida del autor y que describe el proceso de creación de Romeo y Julieta, así como la época y el género dramático. Una vez adquiridos estos conocimientos, el alumnado debía aplicar aquello que había aprendido y trabajar cooperativamente para resolver una serie de enigmas relacionados con la obra de Romeo y Julieta.

RESULTADOS. El alumnado ha adquirido nuevos conocimientos sobre el autor y la obra de una forma lúdica y ha valorado la propuesta del tipo escape room muy positivamente.

DISCUSIÓN. Considerando que actualmente el alumnado desconoce muchos aspectos de la vida y obra de Shakespeare, esta unidad nos permite desarrollar las competencias de la dimensión literaria de una manera activa y motivadora.

\section{Palabras clave}

Innovación pedagógica; Enseñanza secundaria; Lengua inglesa; Breakout edu; Escape room; Literatura; Competencias.

\section{Title}

The escape room as an educational tool to work with literature in secondary education: a practical proposal using Romeo and Juliet Abstract

INTRODUCTION. In recent years, gamification has become an important element of teaching in secondary education. This article discusses the use of educational escape rooms to help children study English-language literature in secondary education. Specifically, it describes an activity for fourth-year students that uses William Shakespeare's Romeo and Juliet as an introduction to the field of literature.

METHOD. The activity started with a screening of John Madden's film Shakespeare in Love, which illustrates the life of the playwright and describes the process of creating Romeo and Juliet as well as aspects of society and of drama as a genre. Working together, the students then had to apply what they had learned to solve a series of enigmas related to Romeo and Juliet.

RESULTS. The students acquired new knowledge about Shakespeare and responded to the escape room activity very positively.

DISCUSSION. Considering that the students to whom this activity was addressed were unfamiliar with the life and work of Shakespeare, the escape room offered the teacher an opportunity to help students acquire competences in the study of literature in an active and motivating way.

Keywords

Pedagogical innovation; Secondary education; English language; Breakout edu; Escape room; Literature; Competences. 
E. Martínez-Borobio i E. Nakova-Katileva. L'escape room com a eina educativa per treballar la literatura a secundària: una proposta pràctica de Julieta

It is in playing and only in playing that the individual

child or adult is able to be creative and to use the whole personality, and it is only in being creative that the individual discovers the self.

Donald Woods Winnicott

\section{Introducció}

Aquest article pretén presentar i valorar una experiència d'innovació que es va crear i dur a terme durant el curs 2018-2019 en un institut públic d'ensenyament secundari a Barcelona. L'activitat es va realitzar al voltant del 23 d'abril, data en què es commemora la mort del dramaturg anglès William Shakespeare i que coincideix amb la Diada de Sant Jordi a Catalunya.

Tradicionalment, la literatura a la classe d'anglès a secundària ha tingut una presència gairebé imperceptible i, quan s'ha tingut en compte, s'ha ensenyat o bé a través de diferents llibres adaptats sobre els quals l'alumnat havia d'omplir una fitxa o contestar unes preguntes de comprensió lectora, o bé mitjançant la lectura de fragments d'obres rellevants. Aquest mètode no assegura que l'alumnat se senti atret per aquesta literatura i que vulgui saber-ne més o vulgui llegir obres clàssiques de forma autònoma i, per tant, si el nostre objectiu és despertar el seu interès, cal un replantejament en la forma de presentar-la.

A Catalunya, el Decret 187/2015, del 25 d'agost, estableix que és necessari aquest canvi metodològic per aconseguir que l'alumnat, en acabar l'etapa de l'educació secundària, assoleixi les competències establertes i, en concret, les competències de la dimensió literària.

Tot i que la història de Romeu i Julieta és força coneguda entre l'alumnat, s'ha observat que aquest coneixement és molt superficial i no va més enllà de la trama de l'obra dramàtica. Per aquest motiu, la proposta didàctica presentada, relacionada amb el currículum competencial i basada en la metodologia coneguda com a ludificació, presenta una obra clàssica de la literatura des d'una perspectiva innovadora i ofereix coneixements sobre l'època de l'autor i el gènere al qual pertany.

Al llarg de l'article es detalla tot el procés que permet replicar l'activitat a qualsevol aula i es descriu la valoració del projecte per part del professorat i l'alumnat implicat.

\section{Marc teòric}

Deterding et al. (2011) van ser els primers autors que van intentar definir la nova tendència en educació que avui coneixem com a ludificació. Segons ells, es tracta de l'ús d'elements del joc en altres situacions per aconseguir un efecte motivador i divertit: «Gamification is the use of game design elements in nongame contexts» (p. 11).

Jaramillo i Castellón Aguayo (2012) duen a terme un estudi sobre neurociència aplicada a la ludificació i descobreixen que durant el joc es crea un cert grau d'addicció que motiva els participants a endinsar-se en el coneixement: 
E. Martínez-Borobio i E. Nakova-Katileva. L'escape room com a eina educativa per treballar la literatura a secundària: una proposta pràctica de Julieta

Un aspecto importante a considerar es que existe un vínculo entre adicción y aprendizaje. Lo interesante del caso es que dicha relación puede utilizarse para crear una educación inmersiva, en la cual el estudiante se introduzca por sí mismo en un campo del conocimiento. (p. 18)

Dins l'àrea de la ludificació educativa, aquesta proposta se centra en un escape room ${ }^{1}$ del tipus breakout edu. Es tracta d'una activitat d'oci alternativa a l'original escape room, que consisteix a tancar un grup d'entre dues i sis persones en un local, en una o diverses habitacions, ple d'enigmes, endevinalles i jocs de lògica. L'objectiu és aconseguir sortir-ne abans del temps màxim fixat. En un escape room educatiu, el joc està relacionat amb les competències i els continguts propis de l'etapa educativa. En el breakout edu s'aconsegueix el mateix resultat, però els enigmes es troben en una caixa que conté les diferents proves tancades amb diferents cadenats. D'aquesta manera el joc es pot realitzar en diferents espais no necessàriament ambientats, cosa que en facilita l'aplicació pràctica als instituts.

Wiemker et al. (2016) destaquen la idoneïtat de la modalitat breakout edu per promoure el pensament crític, treballar cooperativament i incrementar la motivació de l'alumnat.

Per últim, alguns autors han subratllat la importància de l'esforç del docent per a la creació, execució i avaluació del projecte: «Es necesaria una profunda reflexión sobre los objetivos que se quieren alcanzar: una vez determinados, se establecerán las normas que regirán el proceso» (Ortiz-Colón et al., 2018, p. 13).

\section{La unitat didàctica}

En primer lloc, es visualitza la pel-lícula Shakespeare in Love, dirigida per John Madden (1998), i després es treballa la comprensió tant de la pel-lícula com de l'obra escrita mitjançant fragments i tasques d'anàlisi. Pot servir com a pauta el dossier de textos creat per Tom Stoppard on es tracten diferents aspectes dels teatres de l'època de Shakespeare, el context històric i el gènere literari (Stoppard, s. d.): http://www.filmeducation.org/pdf/resources/secondary/ShakespeareInLove.pdf.

Com a suport a aquesta pel-lícula, s'utilitza el bonus feature (Mclntosh, 1999) (https://www.youtube.com/watch?v=FAfih_YUgMk), on els actors i actrius reflexionen sobre qüestions literàries i socials, i sobre elements de la pel-lícula. Es pot utilitzar com a recurs el següent recull de preguntes (Watsonpope, 2018): https://watsonpope.files.wordpress.com/2018/03/shakespeare-in-theclassroom-follow-along-worksheet.pdf.

La tasca final consisteix a resoldre els enigmes d'un escape room educatiu, l'objectiu del qual és que l'alumnat aprofundeixi en el coneixement literari tant de l'escriptor, William Shakespeare, com de la seva obra Romeu i Julieta. Per assolir el repte, l'alumnat ha de superar una sèrie de proves basades, principalment, en la dimensió de la comprensió lectora. L'alumnat treballa de forma cooperativa en grups de 7-8 alumnes, per tant, es reparteixen 4 caixes d'idèntic contingut on troben les proves i activitats que han de fer. A les instruccions inicials es remarca la importància de col-laborar i treballar en equip. A la graella de l'annex s'especifiquen de forma més exhaustiva els objectius i competències als quals vol donar resposta aquesta activitat.

\footnotetext{
${ }^{1}$ Utilitzem el concepte d'escape room en el sentit més ampli d'aquest tipus de joc d'enigmes.
} 
E. Martínez-Borobio i E. Nakova-Katileva. L'escape room com a eina educativa per treballar la literatura a secundària: una proposta pràctica de Julieta

A continuació, es desenvolupa la part de la unitat didàctica dedicada a l'escape room educatiu.

\section{Desenvolupament de les proves}

\subsection{Prova inicial: presentació del repte i sopa de lletres «Shakespeare's works»}

Els alumnes es troben una caixa tancada amb cadenat, una carta escrita en paper de pergamí, una sopa de lletres en DIN-A3 i una graella (vegeu Figura 1). Primer, llegeixen la carta, que es mostra a la Figura 2, on s'hi descriu el problema o repte que han de superar:

You have access to the apothecary's secret room where there are some deadly poisons and some harmless potions. Follow the hints and solve the enigmas in order to find out which is the deadly poison Romeo is about to buy. You have to steal it and avoid the couple's tragic end. You have 50 minutes before Romeo buys the poison. Good luck!

A continuació han de resoldre la sopa de lletres, tot buscant el nom de les obres de William Shakespeare. Un cop les trobin, les han de collocar a la graella i comptar el nombre de lletres $A, R \mathrm{i}$ $T$ que hi apareixen. Això els donarà el codi de 5 dígits que obre el cadenat de la caixa gran. Amb aquesta prova s'activen els coneixements previs sobre l'autor i les seves obres.

\section{Figura 1}

\section{Presentació física del projecte i la sopa de lletres}
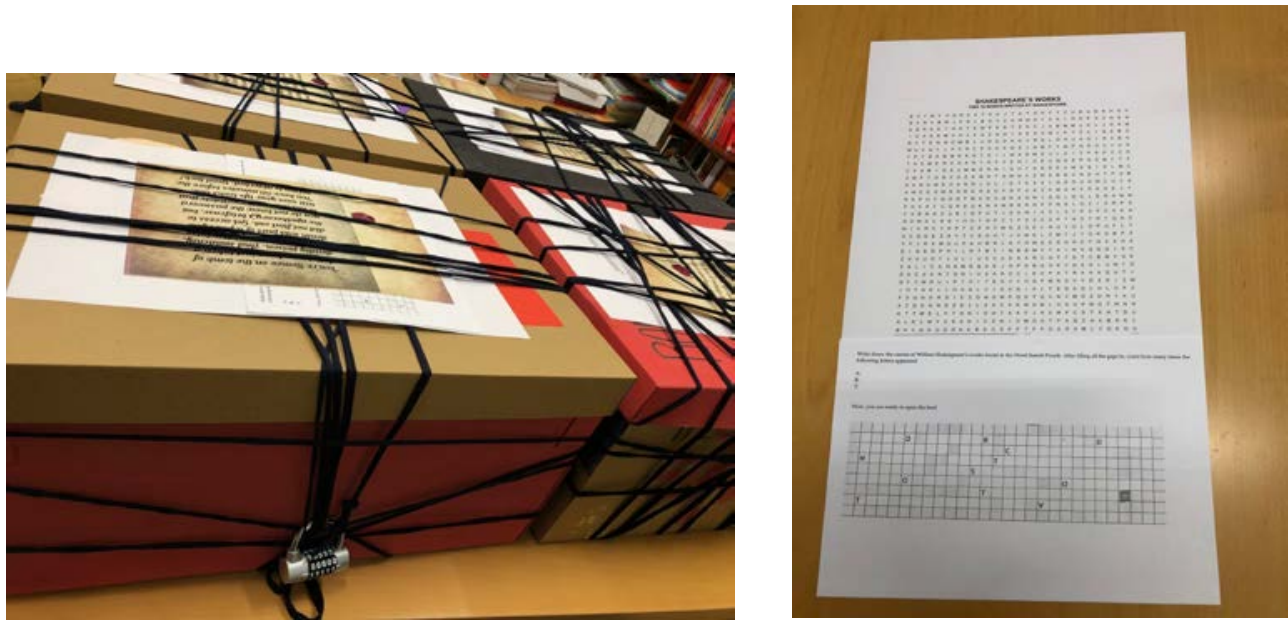
E. Martínez-Borobio i E. Nakova-Katileva. L'escape room com a eina educativa per treballar la literatura a secundària: una proposta pràctica de Julieta

Figura 2

Carta de presentació del problema

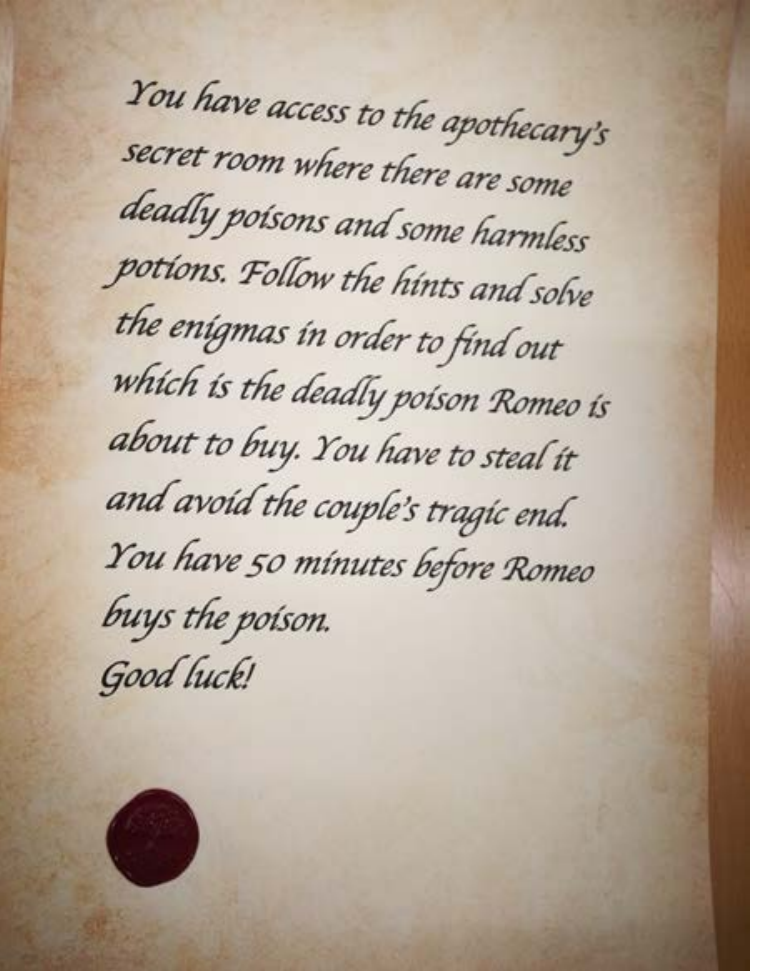

CODI: $(A, R, T) 12,6,15$. Aquest és el codi de 5 dígits del cadenat que obrirà una caixa de cartró gran on hi ha la resta de proves (vegeu Figura 3). L'alumnat ha participat en la creació de l'escape room pintant i decorant aquestes caixes des de la matèria d'Educació Visual i Plàstica.

\section{Figura 3}

Obrint el cadenat per accedir a les proves de l'interior

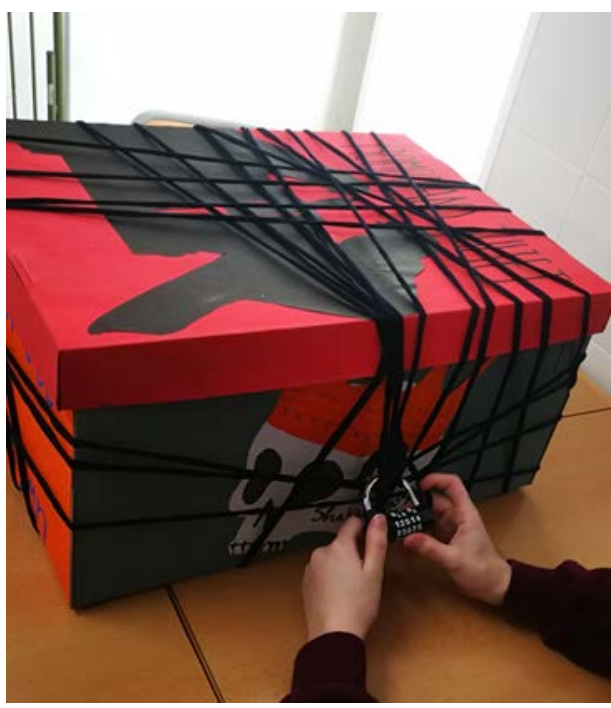


E. Martínez-Borobio i E. Nakova-Katileva. L'escape room com a eina educativa per treballar la literatura a secundària: una proposta pràctica de Julieta

\subsection{Proves dins la caixa gran}

Per realitzar algunes de les proves, a les caixes hi ha un exemplar del llibre Romeo and Juliet en anglès (versió original), com es mostra a la Figura 4, i una tauleta per escanejar els codis QR, obrir cadenats digitals i altres tasques. No hi ha un ordre específic per fer-les, els participants han d'intuir què han de fer per resoldre l'enigma.

\section{Figura 4}

Els llibres que hi ha a dins

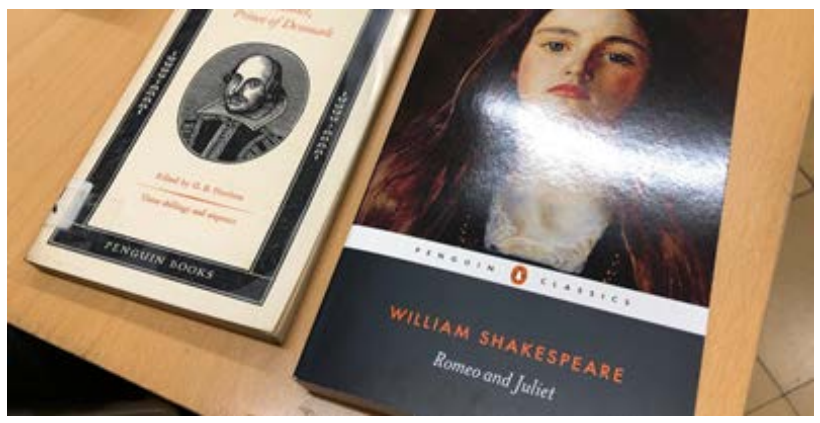

\subsubsection{Balcony scene gap fill}

En aquesta prova (vegeu Figura 5) es presenta un fragment de la famosa escena del balcó de l'obra Romeu i Julieta en el qual hi ha deu espais buits. Els participants han d'omplir aquests buits amb l'ajuda del banc de paraules donat a l'activitat. El fragment està referenciat $i$, per tant, es troba al llibre; en cas de dificultat, l'alumnat en pot fer ús. Després, han de trobar tres paraules directament relacionades amb la llum -twinkle (brillar), brightness (brillantor) $\mathrm{i}$ bright (clar) - i multiplicar entre si els números que els precedeixen $(5 \times 7 \times 8)$. D'aquesta manera obtenen el codi 280. La pista diu que si no s'ha obtingut un número de quatre dígits han de buscar als versos acròstics un quart número. En aquest moment, han de mirar la fitxa Hidden word, on, si contesten les set preguntes correctament, obtenen la paraula acròstic. Al darrere tenen una còpia del pròleg de Romeu i Julieta on es pot llegir el número 2 als versos acròstics (vegeu Figura 6). D'aquesta manera, afegeixen el 2 al codi 280 i aconsegueixen desbloquejar la tauleta (codi 2280).

En aquesta prova es treballa la comprensió lectora, la cerca d'informació i la teoria literària, que corresponen principalment a les competències 4, 6 i 11 . 
E. Martínez-Borobio i E. Nakova-Katileva. L'escape room com a eina educativa per treballar la literatura a secundària: una proposta pràctica de Julieta

Figura 5

Balcony scene gap fill

Balcony scene gap fill

Romeo and Juliet: Balcony Scene, Act 2, Scene 2

Fill in the gaps to complete Romeo's balcony soliloquy with these words:

eye, bright, birds, bold, brightness, cheek, twinkle, heaven, entreat, head

It is my lady, $\mathrm{O}$, it is my love!

$O$ that she knew she werel

She speaks, yet she says nothing: what of that?

Her 1 discourses, I will answer it.

I am too 2

tis not to me she speaks.

Two of the fairest stars in all the 3 .

Having some business, do 4 .

her eyes

To 5. in their spheres till they return.

What if her

eyes were there, they in her 6 .

The 7. of her cheek would shame those stars,

As daylight doth a lamp. Her eyes in heaven

Would through the airy region stream so 8 .

That 9 . would sing and think it were not night.

See how she leans her cheek upon her hand

$O$ that I were a glove upon that hand,

That I might touch that 10.

Code to open the ipad: Multiply the numbers of the missing words directly related to light. Is that a 4 digits number? If not, why don't you try to find the first number in the acrostic verses?

\section{Figura 6}

Prova d'acròstics

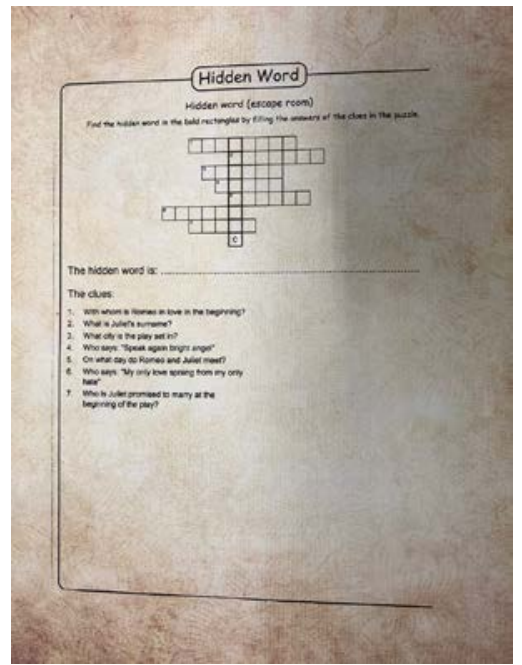

To the Reader.

This Figure, that thou here feeftpus It was for gentle Shakefpert pur, Wherein the Grauer had a ftrife with Nature, to out-doothe life O, could he but haue drawne his wi Aswell in braffe, as he hath hic

Hisface ; the Printwould thenfurpafte All, that vvas euer vvrit in braffe.

But, fince he cannor, Reader, looke Not on his Picture, bur hisBooke. 
E. Martínez-Borobio i E. Nakova-Katileva. L'escape room com a eina educativa per treballar la literatura a secundària: una proposta pràctica de Julieta

\subsubsection{Criptograma del balcó}

En aquesta prova, que es pot observar a la Figura 7, els participants han de resoldre el criptograma, buscar el fragment i seguir llegint per trobar una herba o flor. Aquesta flor és la rosa, i farà que es fixin en la rosa que han trobat dins la caixa. En aquesta part es treballa la lectura i la cerca d’informació específica, corresponents a les competències 4 i 6.

\section{Figura 7}

Criptograma

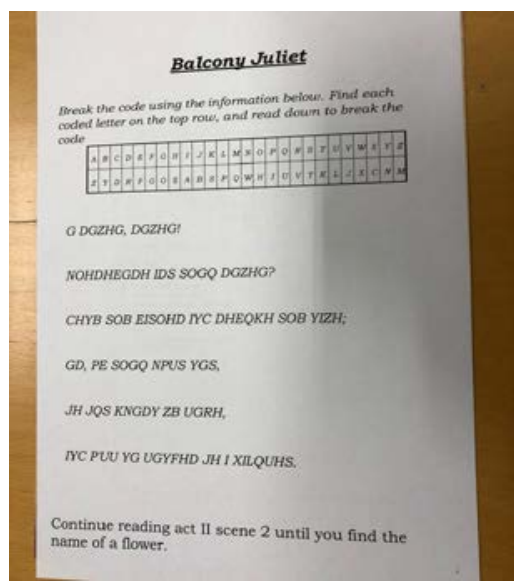

La resposta al criptograma és el famós fragment de l'escena del balcó on la Julieta diu:

O Romeo, Romeo! wherefore art thou Romeo?

Deny thy father and refuse thy name;

Or, if thou wilt not, be but sworn my love,

And I'll no longer be a Capulet.

\subsubsection{La rosa}

Com s'ha replicat a la Figura 8, dins la rosa hi ha un codi QR que els porta a un puzle que han de muntar i que representa l'escena del ball a la festa dels Capulet:

https://www.jigsawplanet.com/?rc=play\&pid=24db0bf8ab86.

Més endavant els participants hauran de tornar-hi per extreure'n informació addicional.

\section{Figura 8}

QR amb puzle
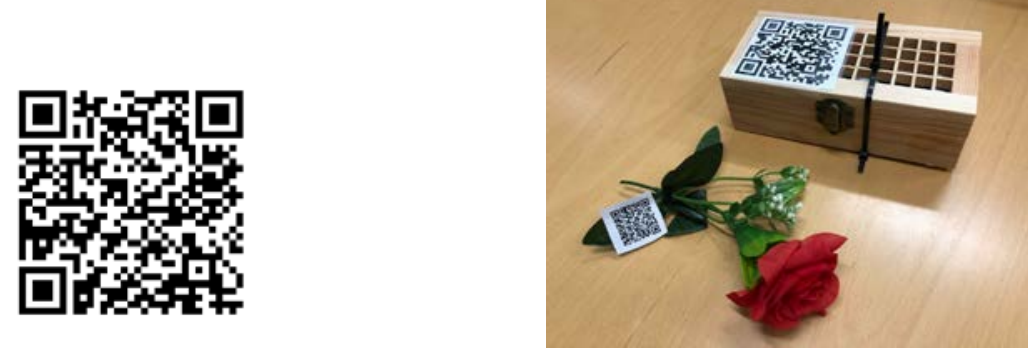
E. Martínez-Borobio i E. Nakova-Katileva. L'escape room com a eina educativa per treballar la literatura a secundària: una proposta pràctica de Julieta

\subsubsection{R\&J in paintings}

En aquesta prova hi ha set pintures que representen escenes de Romeu i Julieta o d'Ofèlia, un altre personatge de Shakespeare, que s'han d'ordenar cronològicament (vegeu Figura 9). Al darrere de cada pintura hi ha el nom de l'autor i un codi QR que porta a una pàgina web on es pot trobar l'any de l'obra. Un cop ordenades les pintures, podran llegir-hi un enllaç web que els dirigeix a un formulari de Google: https://goo.gl/Nf9cJL. Aquest formulari es descriu en l'apartat següent.

\section{Figura 9}

Prova de les pintures

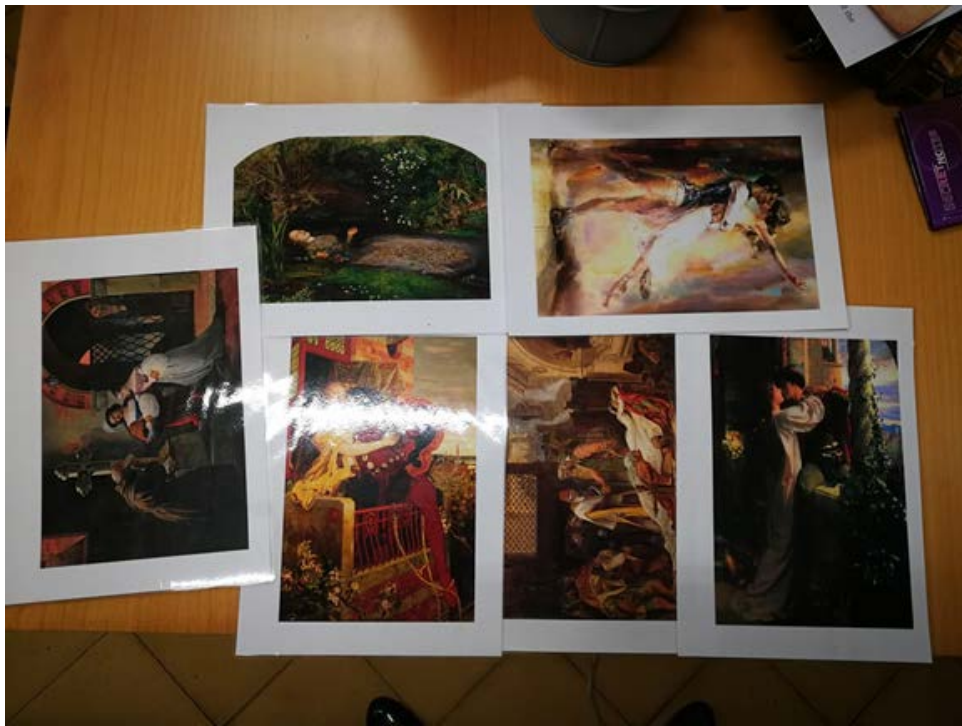

\subsubsection{A colorful garden}

En aquest qüestionari es fan preguntes sobre els colors i les herbes que es mencionen a l'obra. Algunes de les preguntes sobre els colors requereixen recordar les activitats prèvies, realitzades durant la visualització de la pel-lícula o del bonus feature, a més del puzle de l'escena del ball abans esmentat. Pel que fa a les plantes, els fragments per respondre les preguntes estan enganxats als pots que contenen plantes aromàtiques, com es pot observar a la Figura 10. D'aquesta manera, continuem treballant la comprensió lectora (competències 4-6). 
E. Martínez-Borobio i E. Nakova-Katileva. L'escape room com a eina educativa per treballar la literatura a secundària: una proposta pràctica de Julieta

Figura 10

Fragments de les plantes

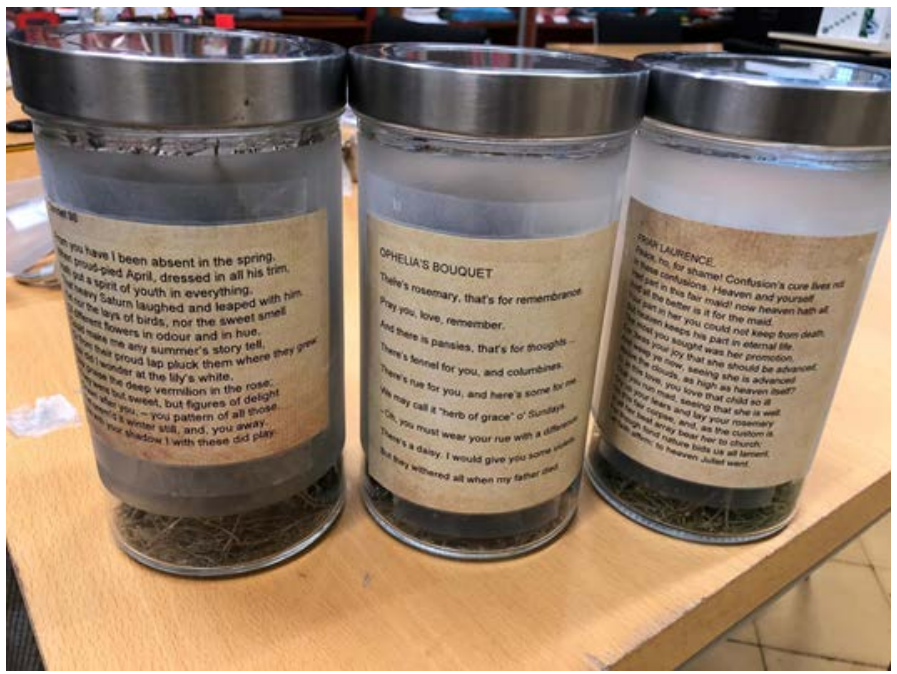

\subsubsection{Plants maze}

En aquesta prova han de trobar el camí que uneix un número d'acte amb un número d'escena. Si ho busquen al llibre, hi trobaran el fragment on la dida compara en Romeu amb el romaní (rosemary) (vegeu Figura 11). Aquesta informació es troba al final del capítol, per tant, l'alumnat haurà de llegir una bona part de l'escena.

\section{Figura 11}

Laberint de les plantes

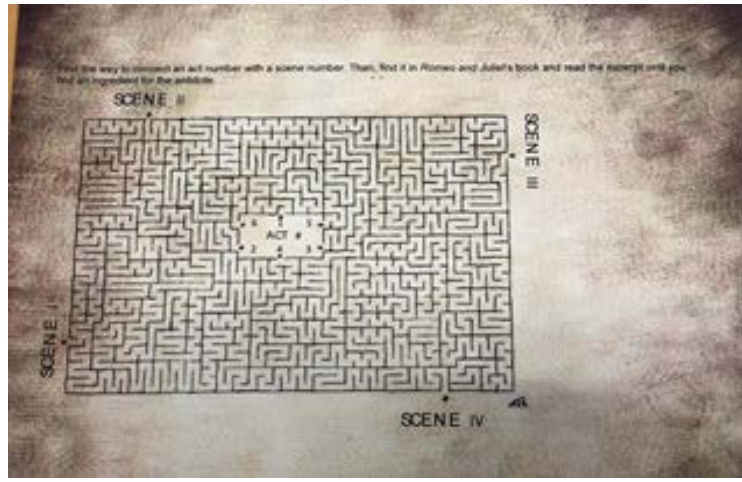

\subsubsection{Números en R\&J}

Per fer aquesta prova els alumnes han d'obrir un primer cadenat tancat amb clau; aquesta clau es pot amagar entre les pàgines del llibre o sota la base dels tubs. Després, han de desmuntar la caixa-puzle i, en aconseguir-ho, obtindran una llum ultraviolada.

A més, a la caixa hi troben una llibreta secret notes, com es mostra a la Figura 12, on llegiran fragments de l'obra relacionats amb números; per exemple, els anys de la Julieta o les hores 
E. Martínez-Borobio i E. Nakova-Katileva. L'escape room com a eina educativa per treballar la literatura a secundària: una proposta pràctica de Julieta que està adormida pels efectes de la poció. Les operacions a seguir estan escrites en tinta invisible. Han de fer càlculs i anar passant aigua d'un tub d'assaig a un altre fent servir la xeringa segons s'indica. Un cop fetes les operacions, obtenen un codi i comproven si és correcte en una pàgina web escanejant el cadenat digital de la caixa final. En cas afirmatiu, poden accedir al seu contingut, descrit a continuació.

Figura 12

Prova de números
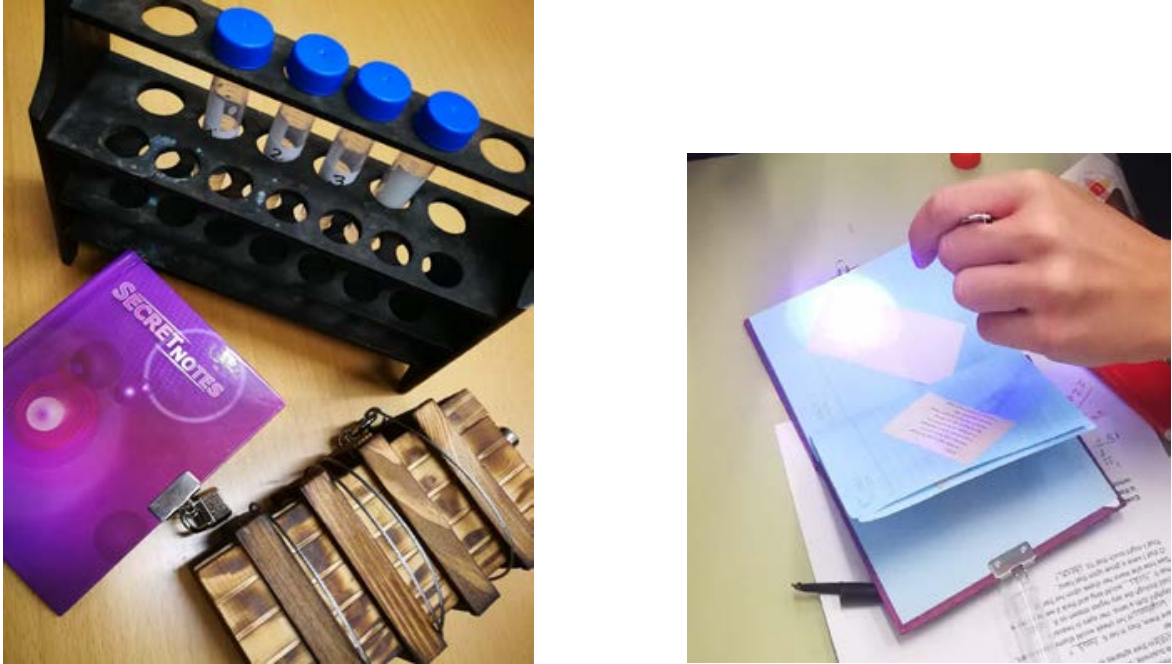

\subsubsection{Apothecary's secret box}

La caixa secreta de l'apotecari conté diferents pots amb pocions, només una de les quals conté el verí letal que en Romeu li comprarà a l'apotecari, si l'alumnat no ho impedeix (vegeu Figura 13). A partir de les respostes de totes les pistes i enigmes que han resolt, els participants han d'identificar el pot que conté el verí. Si ho aconsegueixen, acaben el joc, salven en Romeu i canvien el destí desafortunat de la parella.

Les combinacions de colors i herbes dels pots poden ser aquestes:

1. pansies, tap vermell, líquid verd

2. rosemary, tap gris, líquid blau (aquesta és la resposta correcta)

3. rose, tap groc, líquid verd

4. rose, tap lila, líquid vermell

5. rosemary, tap gris, líquid vermell

6. lily, tap lila, líquid blau

Missatge per ajudar a decidir un color dins la caixa:

The antidote is now before your eyes.

The right combination has the herb you reached in the maze, the same that covered Juliet's corpse. The liquid is the colour of Montague family. The tap is the colour of Juliet's mask in the ball. Think well but fast, Romeo will soon buy the poison! 
Figura 13

Caixa amb tasca final

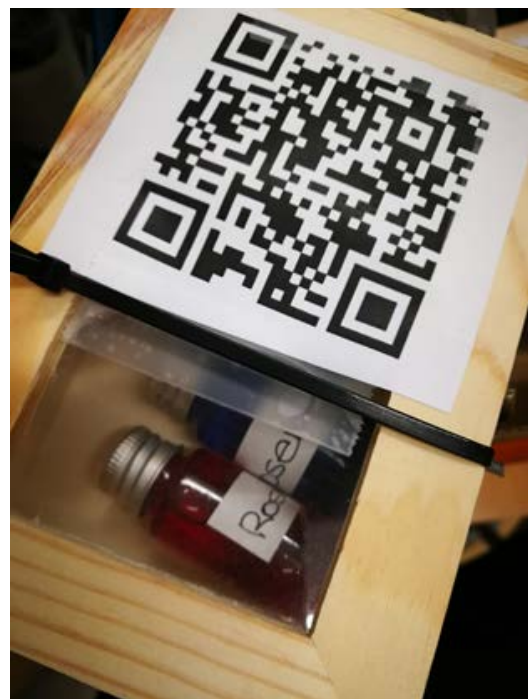

\section{Avaluació}

La manera d'avaluar aquesta proposta didàctica és, principalment, formativa, a través de l'observació directa tant del treball realitzat per l'alumnat durant les classes prèvies a l'escape room com durant el joc. Durant la primera fase (visualització de la pel-lícula, anàlisi de fragments i realització del dossier) es valoraven les dimensions de comprensió lectora i les dimensions de comprensió i expressió oral. Durant la realització de l'escape room es valorava la implicació de l'alumnat en les tasques de treball cooperatiu per resoldre els enigmes, és a dir, es tenia en compte la competència personal i social. A més, el fet que anessin progressant en la resolució de les diferents proves era un indicador que ens mostrava que aconseguien comprendre les idees generals i específiques del text original i de les instruccions $\mathrm{i}$, per tant, assolien la competència de comprensió lectora.

\section{Resultats}

L'escape room es va desenvolupar en tres grups classe i un total de dotze grups. D'aquests, vuit van aconseguir acabar totes les proves en el temps donat (50 minuts). La consecució del repte no només depenia de l'habilitat de comprensió lectora i execució de les proves, sinó també de la capacitat de repartirse les tasques i enllaçar-les entre si.

És important assenyalar que una de les proves, el formulari Google, recollia els resultats de diferents activitats. En observar les respostes de l'alumnat, es van detectar respostes incorrectes, fet que dificultava poder arribar a la prova final amb tota la informació necessària i, per tant, feia inviable aconseguir el repte final. De fet, el formulari Google és una eina que permet descobrir on ha fallat l'alumnat. En aquest cas específic, les respostes correctes se situaven entre un $60 \%$ i un $76 \%$. 
E. Martínez-Borobio i E. Nakova-Katileva. L'escape room com a eina educativa per treballar la literatura a secundària: una proposta pràctica de Julieta

En acabar la unitat didàctica es van observar diverses millores en l'aprenentatge i l'actitud vers la literatura entre els participants. Per conèixer les opinions de l'alumnat implicat, se'ls va enviar un qüestionari amb cinc preguntes relacionades amb la seva experiència, que havien de respondre de forma anònima.

En primer lloc, des del punt de vista docent, es va observar una major participació i interès respecte a la literatura. Per verificar-ho amb certesa es va proposar la pregunta 1 (vegeu Figura 14), en la qual els participants valoraven els nous coneixements que havien adquirit gràcies a la unitat i a l'escape room. A partir de les seves respostes es pot confirmar que la seva percepció del propi aprenentatge és molt alta i demostra que l'activitat els va proporcionar una experiència significativa.

Figura 14

Pregunta 1

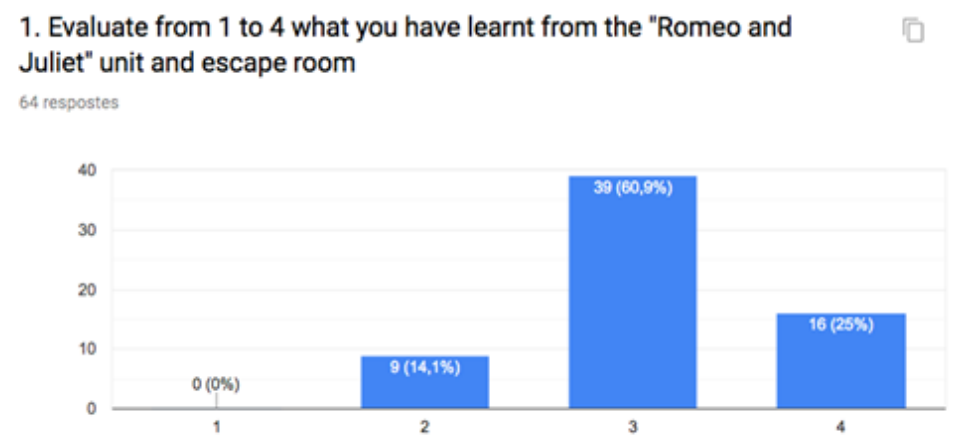

D'altra banda, la proposta ha contribuït a desenvolupar diferents competències de l'aprenentatge, principalment les incloses en la dimensió literària i en la dimensió de comprensió lectora.

Donat que la posada en escena de l'obra de teatre a la pel-lícula de John Madden reprodueix fidedignament fragments de l'obra i que l'escape room inclou nombrosos fragments extrets del text dramàtic en versió original, en acabar la unitat l'alumnat ha tingut contacte amb aproximadament un $70 \%$ del text de Romeu i Julieta.

Les competències de la dimensió literària no només fan referència al fet que l'alumnat llegeixi obres literàries, sinó al fet que conegui els autors i les èpoques més representatius de la literatura anglesa.

Pel que fa a la competència de comprensió lectora, ha estat present durant tot el procés d'ensenyamentaprenentatge; la lectura, tant dels fragments com dels enigmes, i el fet que l'alumnat els resolgués majoritàriament de forma correcta, demostren que s'ha assolit aquesta competència. Així ho confirma la resposta a la pregunta 2 , que es mostra a la Figura 15 , on el $90 \%$ de l'alumnat afirma que nota una millora en la seva capacitat de comprendre textos escrits. 
E. Martínez-Borobio i E. Nakova-Katileva. L'escape room com a eina educativa per treballar la literatura a secundària: una proposta pràctica de Julieta

\section{Figura 15}

Pregunta 2

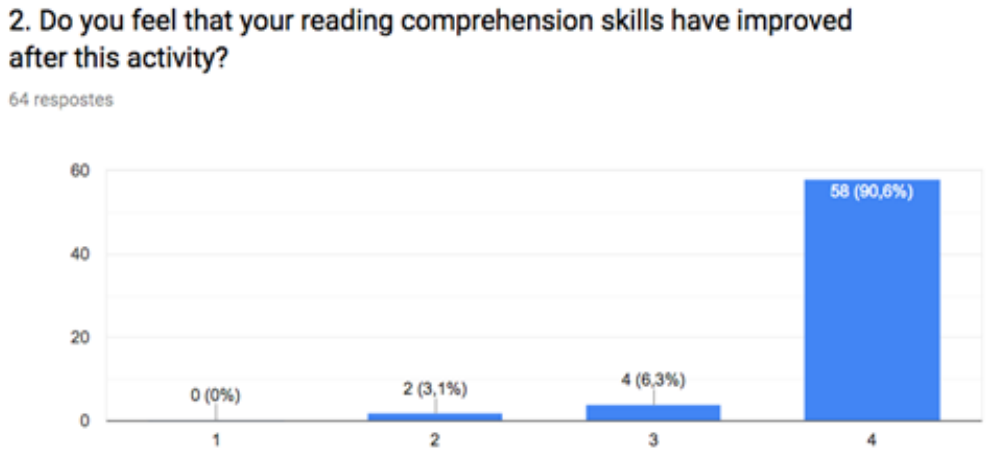

Així mateix, el nivell d'interès i motivació per continuar aprenent sobre l'obra, l'autor i la literatura en general s'ha incrementat. L'alumnat va ser capaç de reflexionar sobre els conceptes de ficció i versemblança, i sobre altres elements literaris, com ara versos acròstics, sonet, estrofa, acte o escena. A partir de la visualització de la pel-lícula, l'alumnat va sentir curiositat i va cercar informació sobre altres personatges i obres que hi apareixien, com Christopher Marlowe, John Webster i la següent obra que va escriure Shakespeare, Twelfth Night. A més, l'alumnat va conèixer els aspectes més representatius del teatre de l'època de la reina Elizabeth, com el context social, la vestimenta i els gèneres, i els va poder comparar amb el teatre que es produïa a Espanya durant el mateix període. La seva resposta a la pregunta 3 , representada a la Figura 16, demostra que gràcies al contacte amb la literatura durant aquesta activitat, la seva motivació per llegir en anglès ha augmentat.

Figura 16

Pregunta 3

3. Are you more motivated to read English literature?

64 respostes

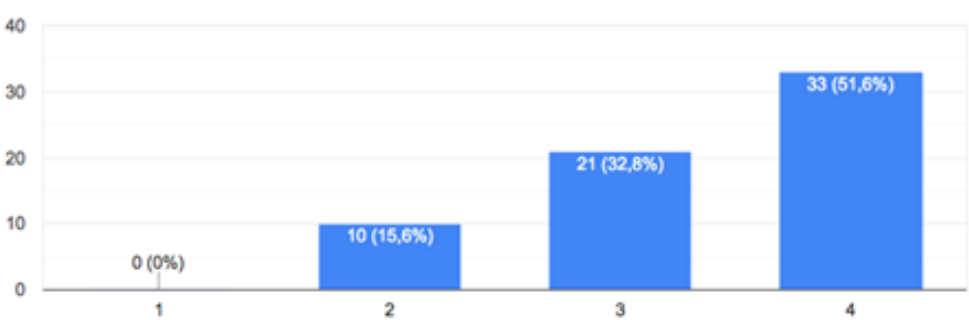

Una altra part fonamental de l'escape room ha sigut el treball col-laboratiu. Els participants s'havien de distribuir les tasques, treballar junts i compartir els dubtes i solucions que anaven trobant; això ha millorat la cohesió grupal i l'aprenentatge. L'opinió dels participants ha estat força positiva, amb un $64 \%$ de resposta completament afirmativa (vegeu Figura 17). 
E. Martínez-Borobio i E. Nakova-Katileva. L'escape room com a eina educativa per treballar la literatura a secundària: una proposta pràctica de Julieta

\section{Figura 17}

Pregunta 4

4. The teamwork helped me learn more and do the tasks better.

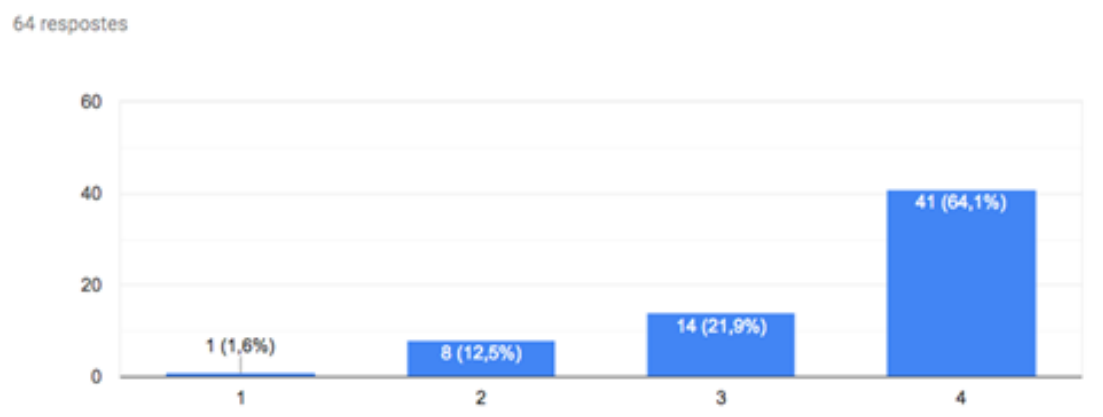

Per últim, els resultats demostren que la present proposta didàctica ha esdevingut un abans i un després per als participants. La seva pròpia valoració és molt alta, com es pot observar a la Figura 18, i confirma que les tasques i els reptes de l'escape room han sigut significatius.

\section{Figura 18}

Pregunta 5

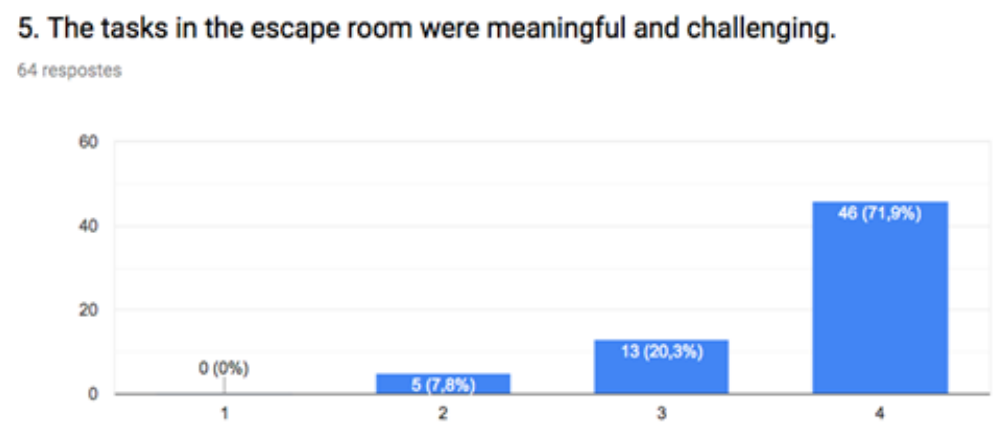

\section{Discussió}

En relació amb els objectius, partint de l'observació i l'avaluació de la proposta es pot concloure que s'han aconseguit els principals objectius d'aprenentatge. L'alumnat ha après diversos aspectes de l'època i del teatre de Shakespeare, i ha adquirit més coneixements sobre literatura: la vida de l'autor i l'obra de Romeu i Julieta, una de les obres més importants de la literatura universal. A més, en la preparació i realització d'aquest joc, l'alumnat ha passat per situacions que requereixen utilitzar estratègies de comunicació oral adequades a la situació comunicativa. Durant la preparació van participar en debats a partir de la informació llegida a la guia docent en els quals havien d'aplicar lèxic específic per expressar opinions, desacord, demanar torn de paraula, etc. Així mateix, en el joc es van aplicar estratègies orals per resoldre problemes.

Des del punt de vista docent, i com a creadores de l'activitat, tant al feedback rebut personalment com al qüestionari de valoració de l'experiència s'ha observat que l'alumnat s'ha implicat molt més que en una 
E. Martínez-Borobio i E. Nakova-Katileva. L'escape room com a eina educativa per treballar la literatura a secundària: una proposta pràctica de Julieta classe tradicional. El nivell de participació i interès abans i durant l'escape room ha incrementat, ja que tothom volia aprendre més per poder resoldre els enigmes amb més eficàcia.

Des del punt de vista de l'alumnat, es va demanar als participants que detectessin els punts forts i febles de l'escape room. Tothom va destacar el caràcter motivador i dinàmic del joc, així com el fet que llegien la versió original de l'autor i descobrien aspectes de l'obra que desconeixien. En els seus comentaris, també van valorar positivament els materials i les tasques que, tot i ser molt diferents, en el seu conjunt portaven a descobrir la solució final. Com a suggeriment, es van demanar més instruccions, cosa que es pot millorar en la propera edició.

Es pot concloure que es tracta d'una proposta molt profitosa que, realitzada un o dos cops a l'any, esdevé una experiència única i memorable.

\section{Agència de suport}

Institut Jaume Balmes 


\section{Referències}

Decret 187/2015, de 25 d'agost, d'ordenació dels ensenyaments de l'educació secundària obligatòria. DOGC núm. 6945. https://portaldogc.gencat.cat/utilsEADOP/PDF/6945/1441278.pdf

Deterding, S., Khaled, R., Nacke, L. E., i Dixon, D. (2011, maig). Gamification: Toward a Definition [Comunicació presentada]. Computer-Human Interaction (CHI) 2011 Workshop, Vancouver, Canadà. http://gamification-research.org/wp-content/uploads/2011/04/02-Deterding-KhaledNacke-Dixon.pdf

Jaramillo, O., i Castellón Aguayo, L. (2012). Educación y videojuegos. Chasqui Revista Latinoamericana de Comunicación, 117, 11-19. https://revistachasqui.org/index.php/chasqui/article/view/201/210

Madden, J. (dir.) (1998). Shakespeare in love [Pel·lícula]. Miramax Home Entertainment.

Mclntosh, S. (dir.) (1999). Shakespeare in Love. Bonus Feature [Vídeo]. Miramax Films / The Department of Education. https://youtu.be/FAfih_YUgMk

Ortiz-Colón, A. M., Jordán, J., i Agredal, M. (2018). Gamificación en educación: una panorámica sobre el estado de la cuestión. Educação e pesquisa, 44, e173773. http://dx.doi.org/10.1590/S16784634201844173773

Stoppard, T. (s. d.). Shakespeare in Love. Study Film Education Guide. Film Education. http://www.filmeducation.org/pdf/resources/secondary/ShakespearelnLove.pdf

Watsonpope (1 de març de 2018). Shakespeare in the Classroom (notes) [Blog]. https://watsonpope.wordpress.com/2018/03/01/shakespeare-in-the-classroom-notes-3-1-18/

Wiemker, M., Elumir, E., i Clare, A. (2016). Escape Room Games: "Can you transform an unpleasant situation into a pleasant one?». A J. Haag, J. Weisenböck, W. Gruber, i C. F. Freisleben-Teutscher (eds.), Game Based Learning - Dialogorientierung \& spielerisches Lernen digital und analog (pp. 5568). Ikon. https://thecodex.ca/wp-content/uploads/2016/08/00511Wiemker-et-al-Paper-EscapeRoom-Games.pdf 